\title{
Short-term overreaction in equity ETFs following extreme one-day returns
}

\author{
Júlio Lobão ${ }^{1}$ \\ (D) https://orcid.org/0000-0001-5896-9648 \\ Email: jlobao@fep.up.pt \\ Ana Isabel Costa ${ }^{1}$ \\ (D) https://orcid.org/0000-0002-8118-3157 \\ Email: anaisabelvcosta@gmail.com \\ 1 Universidade do Porto, Faculdade de Economia, Departamento de Finanças, Porto, Portugal
}

Received on 02.26.2018 - Desk acceptance on 05.11.2018 - $1^{\text {st }}$ version approved on 07.05.2018 - Ahead of print on 03.25.2019

Associate Editor: Fernanda Finotti Cordeiro Perobelli

\begin{abstract}
This paper investigates the short-term price predictability of US equity Exchange Trade Funds (ETFs) in reaction to one-day extreme returns. We also assess the cross-section features associated to price overreaction following extreme price movements. The literature on the short-term overreaction of ETFs is rather scarce. Furthermore, existing studies tend to focus on delimited historical periods, which makes their results difficult to generalize. Our paper fills this gap by considering a comprehensive sample of ETFs over an extended period of time. In addition, we are the first to study the effect of the prevailing market trend and of liquidity on the patterns of overreaction and subsequent price reversal of ETFs. Being the major ETFs the most actively traded equity securities on the US stock exchanges, their performance and characteristics are of interest by themselves. Our findings suggest that market regulators should concentrate their resources on overseeing the ETF pricing that occurs after-hours. For market practitioners, our results indicate the existence of profitable market opportunities after large price movements. In the present study, we tested the significance of the mean returns for the period immediately after extreme returns. We also conducted a multivariate analysis where the price reversal was regressed against the cross section features of the ETFs under study. We contribute to the literature on ETF price formation as we document, for the first time, the existence of a stark contrast in the reaction to extreme price movements in these assets during normal hours and afterhours periods. On average, the extreme returns that occur in the after-hours period represent an overreaction, leading to a price reversal in the following period. In addition, we show that both tax-motivated trading and noise trading play a role in the pattern of ETF overreaction and reversal.
\end{abstract}

Keywords: equity ETFs, overreaction, short-term reversal, normal hours - after-hours return, price predictability. 


\section{INTRODUCTION}

The creation of Exchange Trade Funds (ETFs) is one of the most spectacular successes in financial innovation in the last decades. Today, the major ETFs are the most actively traded equity securities on the US stock exchanges. The US ETF market remains the largest in the world, accounting for more than 70 percent of ETF assets worldwide. Data from the Investment Company Institute show that by February 2017, 1,736 ETFs were listed in the US for assets worth $\$ 1.73$ trillion. These numbers attest to the widespread demand for ETFs by market participants. For retail investors seeking to gain exposure to broad market indexes, particular sectors or geographical regions, ETFs are a convenient, cost-effective tool. And institutional investors, including mutual funds and pension funds, use ETFs to invest in markets, manage investor flows, or hedge their exposures.

Since ETFs have become such an important investment vehicle in terms of both trading volume and dollar value outstanding, their performance and characteristics are of interest by themselves. In this paper, we conduct the most comprehensive investigation to date about the response to the changes in the price of ETFs that occur within both normal trading hours and after-hours (more than $+5 \%$ or less than -5\%). Using an extensive sample of 36,962 extreme price changes of US ETFs over the 2007-2014 period, we compare the normal hours returns ('open- to-close') and after-hours returns ('close-to-open') for a group of 847 equity ETFs. We also segment the sample by ETF type and conduct a cross-sectional analysis to understand which factors may account for the existence of under/overreaction following extreme price movements.

We document a stark contrast between what occurs in normal hours and after-hours. On average, only extreme returns that occur after-hours represent an overreaction, causing a reversal in the subsequent period. This result supports the proposition that normal and after-hours periods may be regarded as two distinct markets and suggests that markets during after-hours tend to be significantly more inefficient. Based on multivariate analyses, we show that the magnitude of the reversal tends to be conditional on the size of the previous extreme return. Moreover, our findings suggest that both taxmotivated trading and noise trading play a role in the pattern of ETF overreaction and reversal. The implications of our results to both regulators and market practitioners are addressed in conclusions.

The remainder of the paper is structured as follows. We review the related literature in the second section. The third section describes the data and methods. The empirical results are presented and discussed in the fourth section. The final section provides a conclusion.

\section{LITERATURE REVIEW}

A considerable body of empirical literature exists on the overreaction of prices after large price increases and declines. Using a sample of stocks listed on the NYSE, De Bondt and Thaler (1985) showed that stocks that had registered the lowest returns over the previous three or five years did better during the following three to five years than those that had previously had the highest positive returns. A contrarian strategy would yield an annual abnormal market adjusted return of $24.6 \%$ for the arbitrage portfolio.

Inspired by that study for long-run stock returns, other authors document short-term market overreaction after large one-day price changes. For example, using US daily data from 1975 to 1984, Atkins and Dyl (1990) showed that stock prices overreacted in the short-term, especially to negative information. Stocks that experience a one-day price increase (or decline) of more than $10 \%$ display abnormally negative (or positive) returns the next trading day.

Bremer and Sweeney (1991), Cox and Peterson (1994), and Choi and Jayaraman (2009) offer corroborating evidence for the US market. For the period between 1962 and 1986, Bremer and Sweeney (1991) examined stock returns of firms listed in the Fortune 500 that show price declines of more than $10 \%$ in a day and also found strong price reversals in the days after the drop. The first day shows a return of $1.77 \%$ above average and rises cumulatively to $2.23 \%$ over the two days after the price shock.

Cox and Peterson (1994) studied large one-day stock price decreases (a return of -10\% or lower) and subsequent returns over a twenty-day period. They partitioned their 
sample period (1963 to 1991) into five-year intervals to analyze stock price overreaction over time. The authors found significant reversals of price decreases, too, but only for the period before 1987. Cox and Peterson (1994) conclude that price reversals in short-term can be explained by the bid-ask bounce and by the degree of market liquidity, and that overreaction vanishes with rising market liquidity.

Choi and Jayaraman (2009) analyzed the 1996-2004 period for the NYSE, AMEX and NASDAQ and found overreaction patterns up to two days after a large price decline (at least 10\%), but only for nonoptional stocks.

Outside the US, there are also studies on short-term overreaction. For example, Bremer, Hiraki, and Sweeney (1997) examined daily returns of stocks included in the NIKKEI 300 index and found price reversals after large one-day stock price drops. And Bowman and Iverson (1998) and Otchere and Chan (2003) concluded that short-term overreaction did exist in New Zealand and Hong Kong, respectively.

More recently, Spyrou, Kassimatis, and Galariotis (2007) and Mazouz, Joseph and Joulmer (2009) found results for the UK that seem to contradict the overreaction hypothesis. Spyrou et al. (2007) report that the market reaction to shocks for large capitalization stock portfolios in the 1989-2004 period was consistent with the efficient market hypothesis. Mazouz et al. (2009) found no evidence of overreaction to large one-day price changes except following negative shocks of very large magnitude (more than 15\%).

Lobe and Rieks (2011) document evidence of overreaction in the German stock market between 1988 and 2007 for stocks experiencing a price change of $10 \%$ or more in either direction. However, due to transaction costs, the effect can hardly be exploited.

On the contrary, Caporale, Gil-Alana, and Plastun (2017) show that short-term overreactions in various financial markets (stock markets, foreign exchange markets, commodity markets) cause the emergence of temporary market inefficiencies that could result in extra profit opportunities.

The literature on ETFs' overreaction is rather limited. Madura and Richie (2004) showed that US ETFs during the dot-com bubble were prone to intraday overreaction and reversal which could be profitably exploited by contrarian day-traders. They found greater overreaction in ETFs that were more volatile and in international ETFs. Similarly, Simon and Sternberg (2005) concluded that German, UK and French equity ETFs trademarked by "iShares" overreacted to market developments after European markets closed, and Tse and Martinez (2007) argued that noise traders created excessive volatility in the price of 24 iShares funds traded in the US from 2002 through 2004. Finally, Levy and Lieberman (2013) used intraday data to conclude that ETF returns during nonsynchronized trading hours (i.e., when the underlying markets and US markets have no overlapping trading hours) express a behavioral bias where traders overreact to local US market sentiment.

Overall, the literature indicates that overreaction is generally found after extreme one-day returns, being especially significant following price decreases. For the studies dealing with profitability issues, most studies suggest that no abnormal returns could have been obtained in-sample.

\section{DATA AND METHODS}

Our sample comprises observations of daily opening and closing prices for all the NYSE-traded equity ETFs between January 2007 and December 2014. Daily price data covering the 847 ETFs were obtained from the Bloomberg database.

Daytime returns are estimated as the log difference between the closing and opening prices on day $t$. Overnight returns are the log difference between the opening price on day $t$ and the closing price on day $t-1$. Daytime period and overnight period jointly cover a total of twenty-four hours.

Based on Madura and Richie (2004), the sample is further partitioned by ETF type. ETFs can be classified as sector, broad-based, or international, and enable investors to gain exposure to different segments of the market.
Broad-based ETFs like the iShares Dow Jones US Total Market Index Fund or the SPDR allow the investor to cover US equities with a single ETF. Sector funds like the Barclays iShares Dow Jones Sector allow investment in the stocks of different industrial sectors. Finally, international ETFs like the iShares MSCI Germany Index Fund allow investors to achieve exposure to international markets. Our sample includes 285 broad-based ETF, 329 sector ETF and 233 international ETF.

For a one-day period, the trigger to qualify for a sample in other analysis of individual stocks is usually a daily absolute return of $10 \%$ or higher (e.g., Cox \& Paterson, 1994; Choi \& Jayaraman, 2009). Since ETFs track a combination of stocks and should not be as volatile as single stocks, we adopt a minimum trigger of $5 \%$. 
The number of extreme price increases (winners) and decreases (losers) across normal and after-hours periods by different types of ETFs are shown in Table 1 (Panel A). The entire sample includes 36,062 extreme ETF price changes that meet the minimum 5\% trigger level. A total of 22,596 (62.66\%) observations qualify during normal hours versus 13,466 (37.44\%) after-hours. As Panel B shows, of the entire sample, 18,952 (52.55\%) are losers, and the remaining 17,110 (47.45\%) are winners. In all ETF types considered, the number of losers is higher than the number of winners. Our data also indicate that most of extreme price variations refer to the sector ETFs. Panel B of Table 1 shows that $47 \%$ of the 22,596 movements during normal hours and that $39 \%$ of the 13,466 movements during after-hours can be attributed to sector ETFs.

The ratio of normal hours observations versus afterhours varies by ETF type. The normal hours observations dominate for broad-based ETFs and for sector ETFs but in international ETFs the number of after-hours observations is higher.

Table 1

Distribution of equity ETF sample that meets the 5\% minimum trigger level

\begin{tabular}{|c|c|c|c|c|c|c|c|c|c|c|}
\hline \multicolumn{11}{|c|}{ Panel A: Distribution of winners and losers across normal hours and after-hours } \\
\hline & \multicolumn{4}{|c|}{$\begin{array}{c}\text { Winners } \\
\text { (positive triggers) }\end{array}$} & \multicolumn{4}{|c|}{$\begin{array}{c}\text { Losers } \\
\text { (negative triggers) }\end{array}$} & \multicolumn{2}{|c|}{ Total } \\
\hline & \multicolumn{2}{|c|}{ Normal hours } & \multicolumn{2}{|c|}{ After-hours } & \multicolumn{2}{|c|}{ Normal hours } & \multicolumn{2}{|c|}{ After-hours } & & \\
\hline International ETF & 1,774 & $20 \%$ & 2,308 & $26 \%$ & 2,458 & $28 \%$ & 2,259 & $26 \%$ & 8,799 & $100 \%$ \\
\hline Broad-Based ETF & 3,565 & $31 \%$ & 1,904 & $17 \%$ & 4,165 & $36 \%$ & 1,787 & $16 \%$ & 11,421 & $100 \%$ \\
\hline Sector ETF & 4,750 & $30 \%$ & 2,809 & $18 \%$ & 5,884 & $37 \%$ & 2,399 & $15 \%$ & 15,842 & $100 \%$ \\
\hline Entire Sample & 10,089 & $28 \%$ & 7,021 & $19 \%$ & 12,507 & $35 \%$ & 6,445 & $18 \%$ & 36,062 & $100 \%$ \\
\hline \multicolumn{11}{|c|}{ Panel B: Distribution of subsamples across types of ETF } \\
\hline & \multicolumn{2}{|c|}{ Total normal hours } & \multicolumn{2}{|c|}{ Total after-hours } & \multicolumn{2}{|c|}{ Total winners } & \multicolumn{4}{|c|}{ Total losers } \\
\hline International ETF & 4,232 & $19 \%$ & 4,567 & $34 \%$ & 4,082 & $24 \%$ & \multicolumn{2}{|c|}{4,717} & \multicolumn{2}{|c|}{$25 \%$} \\
\hline Broad-Based ETF & 7,730 & $34 \%$ & 3,691 & $27 \%$ & 5,469 & $32 \%$ & \multicolumn{2}{|c|}{5,952} & \multicolumn{2}{|c|}{$31 \%$} \\
\hline Sector ETF & 10,634 & $47 \%$ & 5,208 & $39 \%$ & 7,559 & $44 \%$ & \multicolumn{2}{|c|}{8,283} & \multicolumn{2}{|c|}{$44 \%$} \\
\hline Entire Sample & 22,596 & $100 \%$ & 13,466 & $100 \%$ & 17,110 & $100 \%$ & \multicolumn{2}{|c|}{18,952} & \multicolumn{2}{|c|}{$100 \%$} \\
\hline
\end{tabular}

Source: Prepared by the authors.

Following Brown and Warner (1980), we employ a mean-adjusted returns model to analyze the occurrence of overreaction occurring after a large price variation. Expected returns are computed using a 255-day estimation window that ends fifteen days before the event.

We apply the testing framework of Madura and Richie (2004) to our dataset. Thus, the time horizon used to test for a reversal is either the after-hours period following prior extreme price variations during normal trading hours, or the normal hours subsequent to extreme price movements observed during the previous after-hours period.

We conducted a cross-sectional analysis to understand which factors may account for the occurrence of overreaction following extreme price movements. We considered the abnormal returns in reaction to extreme price movements to be conditional on the following characteristics: 1 ) the period under analysis (normal hours versus after-hours);2) the size of the extreme return (trigger) of the ETF; 3) the type of ETF; 4) the volatility of the ETF; 5) the trading volume of the ETF; 6) the prevailing trend (bullish versus bearish) in the stock market; and 7) the existence of tax effects.

An extreme price variation is classified according to whether it occurred in normal hours or after-hours with a binary variable. One should expect a larger overreaction after-hours since the literature suggest that prices on this period are less efficient (e.g., Barclay \& Hendershot, 2003; Berkman, Koch, Tuttle, \& Zhang, 2012).

The trigger is assessed as the return that allowed the ETF to qualify for the sample based on the $+5 \%$ or $-5 \%$ threshold level. We expect that a more extreme price movement may mean a greater overreaction, thus leading to a larger reversal.

Each ETF is categorized as international, broad-based, or sector. The three kinds of ETFs are classified in separate using binary variables standing for sector ETFs and international ETFs. It is plausible to admit that different 
ETF types may exhibit different sensitivities to pricing factors. For example, broad-based ETFs are expected to be subject to lower levels of overreaction because they represent a broadly diversified holding of US stocks.

ETF volatility is captured by the abnormal standard deviation of returns over the past ninety days. The abnormal standard deviation of returns is computed as the difference between the standard deviation of returns observed over the past ninety days before the trigger day and the standard deviation of returns in the 255day estimation window ending fifteen days before the event. The expected relationship between overreaction and volatility is not clear. In fact, while Brown, Harlow, and Tinic (1993) report a positive correlation between abnormal post-extreme price movement returns and shifts in return volatility, it is also plausible to conjecture that the presence of noise traders in the market - proxied by a heightened volatility in prices - may drive informed investors off the market, thus mitigating the magnitude of short-term price reversals.

An ETF's liquidity is measured as the abnormal daily trading volume for the period in which the trigger happened. The abnormal daily trading volume is defined as the difference between the trading volume observed in the trigger day and the average daily volume of trading in the 255-day estimation period ending fifteen days prior to the event. According to Cox and Peterson (1994), more liquid ETFs should be less prone to mispricing (and therefore to overreaction) because a sufficient number of informed investors is involved.

We applied the method proposed by Pagan and Sossounov (2003) to capture the prevailing trend (bullish versus bearish) in the US stock market, represented by the S\&P500 index. The literature suggests that prices may be more susceptible to temporary mispricing when the market sentiment typical of bullish trends is higher (e.g., Stambaugh et al., 2012). Moreover, Davis, Madura, and Marciniak (2009), in an analysis of the performance of US ETFs during the 2007-2009 crisis, suggest that the degree of overreaction in ETF prices was associated with the price runnup preceding the financial crisis.

The reaction to an extreme return may be partially explained by tax reasons. Thus, a binary variable was used to classify extreme price movements according to whether they occurred in December or January. De Bondt and Thaler (1987) show that price reversals have a very strong seasonal pattern: significant price reversals associated with loser stocks occur only in January. This suggests that tax loss selling may play a role especially on loser reversals.

Finally, year dummies were used to account for unobservable time-specific factors.

We employ the following multivariate model to all winners and losers to test for the impact of the trading period (normal versus after-hours) while controlling for a set of other variables:

$$
\begin{aligned}
& \text { AR }_{\mathrm{i}}=\beta_{0}+\beta_{1} \text { AFTERHOURS }_{\mathrm{i}}+\beta_{2} \text { TRIGGER }_{\mathrm{i}}+\beta_{3} \text { INTLDUM }_{\mathrm{i}}+\beta_{4} \text { SECTDUM }_{\mathrm{i}} \\
&+\beta_{5} \text { ABN_VOLATILITY }_{\mathrm{i}}+\beta_{6} \text { ABN_VOLUME }_{\mathrm{i}}+\beta_{7} \text { BULLDUM }_{\mathrm{i}} \\
&+\beta_{8} \text { TAXDUM }_{\mathrm{i}}+\beta_{9} \text { YEAR08 }+\beta_{10} \text { YEAR09 }+\beta_{11} \text { YEAR10 } \\
&+\beta_{12} \text { YEAR1 }+\beta_{13} \text { YEAR1 }+\beta_{14} \text { YEAR13 }+\beta_{15} \text { YEAR14 } \varepsilon_{\mathrm{i}}
\end{aligned}
$$

where:

$\mathrm{AR}=$ abnormal return during the period following the extreme return,

AFTERHOURS $=$ the binary variable, with a value of 1 if the return occurs after-hours and 0 otherwise,

TRIGGER $=$ return of the ETF (must be $>+5 \%$ or $<-5 \%$ ), INTLDUM = the binary variable, with a value of 1 if the ETF is an international fund and 0 otherwise,

SECTDUM = the binary variable, with a value of 1 if the ETF is a sector fund and 0 otherwise,

ABN_VOLATILITY $=$ the abnormal standard deviation of returns observed over the past ninety days before the extreme return occurs,

ABN_VOLUME $=$ abnormal volume of shares trading in the trigger day,
BULLDUM = the binary variable, with a value of 1 if the stock market is in a bullish trend when the extreme price movement occurs and 0 otherwise,

TAXDUM $=$ the binary variable, with a value of 1 if the extreme return occurs during December or January and 0 otherwise, and

YEAR08, YEAR09, YEAR10, YEAR11, YEAR12, YEAR13 and YEAR14 = binary variables, with a value of 1 if the extreme return occurs in the year 2008, 2009, 2010, 2011, 2012, 2013 or 2014, respectively, and 0 otherwise.

The model was tested for heteroscedasticity and corrected using White's test.

We also adapted the model to examine the crosssectional variation in abnormal returns for the normal hours and after-hours in separate. In this case, the 
AFTERHOURS variable is excluded, being replaced by the binary variable LOSDUM, to distinguish losers from winners. LOSDUM is assigned a value of 1 if the extreme return is negative and 0 otherwise.

\section{RESULTS}

\subsection{Abnormal Returns Subsequent to the Extreme Price Movements of ETFs}

Table 2 shows the abnormal returns in the sequence of after-hours triggers that occurred for the full sample of winners and losers and the different subsamples. For the winners and losers, the results are displayed for trigger levels of at least $5 \%$, at least $6 \%$, and at least $7 \%$.

As shown in Table 2, the after-hours winners undergo a significant negative return in normal hours, regardless of the trigger level. At least 57\% experienced negative abnormal returns in normal hours. The reversal in normal hours suggests that the extreme returns that happened after-hours reflect an overreaction. It is noteworthy, in the last two columns of table 2, that between one quarter and one third of the mean extreme price movement of winners is overturned for the subsamples subdivided by different minimum trigger levels. In general, a significant reaction comes after an extreme price movement occurred after-hours. This suggests that some investors that trade in normal hours take advantage on the overreaction that happened overnight.

Although most of the reversal is concentrated on the normal hours period following the after-hours period where the extreme return occurred, it is interesting to notice that abnormal returns continue to be significantly negative in the subsequent after-hours period. This indicates that the reversal movement in normal hours was not incorrect, and thus seems to verify that the initial extreme price variation was in fact an overreaction.

The magnitude of the reversal in normal hours, during the subsequent after-hours period, and over the combination of these two periods, is larger when a higher trigger level is used. For example, the ETFs that meets the minimum $+5 \%$ trigger have a mean abnormal return of $-1.73 \%$ in normal hours, while the ETFs that meet the minimum $7 \%$ trigger level experience a mean abnormal return of $-3.38 \%$. Comparable results hold for the twentyfour-hour period following the after-hours period when the extreme return was observed.

Table 2

Whole sample of abnormal returns after after-hours triggers

\begin{tabular}{|c|c|c|c|c|c|c|}
\hline & After-hours & Normal hours & After-hours & 24 hours & \multirow{2}{*}{$\begin{array}{l}\text { Continuation (+) or } \\
\text { reversal }(-) \text { in the } \\
\text { following period } \\
\text { in proportion } \\
\text { to the initial } \\
\text { extreme return }\end{array}$} & \multirow{2}{*}{$\begin{array}{l}\text { Continuation }(+) \\
\text { or reversal (-) in } \\
\text { the following } 24 \\
\text { hours in proportion } \\
\text { to the initial } \\
\text { extreme return }\end{array}$} \\
\hline & Period 0 & Period 1 & Period 2 & (Period 1-2) & & \\
\hline \multicolumn{7}{|c|}{ Panel A. Winners (positive triggers) } \\
\hline \multicolumn{7}{|c|}{ Trigger level } \\
\hline$>=5 \%$ & $7.50 \%$ & $-1.73 \%$ & $-0.07 \%$ & $-1.80 \%$ & $-23.09 \%$ & $-24.02 \%$ \\
\hline \multirow[t]{2}{*}{$(\mathrm{N}=7021)$} & $(78.20)^{* * *}$ & $(-14.00)^{* * *}$ & $(2.60)^{* * *}$ & $(-23.60)^{* * *}$ & & \\
\hline & $100 \%: 0 \%$ & $43 \%: 57 \%$ & $46 \%: 54 \%$ & & & \\
\hline$>=6 \%$ & $8.75 \%$ & $-2.46 \%$ & $-0.05 \%$ & $-2.50 \%$ & $-28.05 \%$ & $-28.60 \%$ \\
\hline \multirow[t]{2}{*}{$(\mathrm{N}=4388)$} & $(62.76)^{* * *}$ & $(-13.53)^{* * *}$ & $(2.86)^{* * *}$ & $(-38.23)^{* * *}$ & & \\
\hline & $100 \%: 0 \%$ & $39 \%: 61 \%$ & $46 \%: 54 \%$ & & & \\
\hline$>=7 \%$ & $9.97 \%$ & $-3.38 \%$ & $-0.01 \%$ & $-3.38 \%$ & $-33.86 \%$ & $-33.92 \%$ \\
\hline \multirow[t]{2}{*}{$(\mathrm{N}=2888)$} & $(51.38)^{* * *}$ & $(-13.44)^{* * *}$ & $(2.92)^{* * *}$ & $(-10.77)^{* * *}$ & & \\
\hline & $100 \%: 0 \%$ & $35 \%: 65 \%$ & $46 \%: 54 \%$ & & & \\
\hline
\end{tabular}


Table 2

Cont.

\begin{tabular}{|c|c|c|c|c|c|c|}
\hline & After-hours & Normal hours & After-hours & 24 hours & \multirow{2}{*}{$\begin{array}{l}\text { Continuation }(+) \text { or } \\
\text { reversal }(-) \text { in the } \\
\text { following period } \\
\text { in proportion } \\
\text { to the initial } \\
\text { extreme return }\end{array}$} & \multirow{2}{*}{$\begin{array}{l}\text { Continuation (+) } \\
\text { or reversal (-) in } \\
\text { the following } 24 \\
\text { hours in proportion } \\
\text { to the initial } \\
\text { extreme return }\end{array}$} \\
\hline & Period 0 & Period 1 & Period 2 & (Period 1-2) & & \\
\hline \multicolumn{7}{|c|}{ Panel B. Losers (negative triggers) } \\
\hline \multicolumn{7}{|c|}{ Trigger level } \\
\hline$<=-5 \%$ & $-7.53 \%$ & $1.41 \%$ & $0.44 \%$ & $1.85 \%$ & $-18.80 \%$ & $-24.64 \%$ \\
\hline \multirow[t]{2}{*}{$(N=6445)$} & $(-68.89)^{* * *}$ & $(16.70)^{* * *}$ & $(7.36)^{* * *}$ & $(20.64)^{* * *}$ & & \\
\hline & $0 \%: 100 \%$ & $69 \%: 31 \%$ & $28 \%: 72 \%$ & & & \\
\hline$<=-6 \%$ & $-8.94 \%$ & $1.94 \%$ & $0.52 \%$ & $2.46 \%$ & $-21.72 \%$ & $-27.53 \%$ \\
\hline \multirow[t]{2}{*}{$(\mathrm{N}=3827)$} & $(-53.81)^{* * *}$ & $(15.31)^{* * *}$ & $(6.27)^{* * *}$ & $(17.80)^{* * *}$ & & \\
\hline & $0 \%: 100 \%$ & $62 \%: 38 \%$ & $54 \%: 46 \%$ & & & \\
\hline$<=-7 \%$ & $-10.32 \%$ & $2.67 \%$ & $0.56 \%$ & $3.23 \%$ & $-25.85 \%$ & $-31.26 \%$ \\
\hline \multirow[t]{2}{*}{$(N=2437)$} & $(-43.33)^{* * *}$ & $(14.62)^{* * *}$ & $(5.21)^{* * *}$ & $(37.18)^{* * *}$ & & \\
\hline & $0 \%: 100 \%$ & $65 \%: 35 \%$ & $54 \%: 46 \%$ & & & \\
\hline
\end{tabular}

Notes: Proportion of positive observations: proportion of negative observations shown in italics.

*,** and *** represent significance at the $10 \%, 5 \%$ and $1 \%$ levels, respectively, using a 1-tailed test for significance.

Source: Prepared by the authors.

Table 2 also shows that the after-hours losers undergo a statistically significant reversal in normal hours for all trigger levels. While the proportion of positive and negative observations vary with the minimum trigger level used, at least $62 \%$ experienced positive abnormal returns in normal hours period. These results suggest that the market overreacted in the case of after-hours loser ETFs. As with after-hours winners, most of the positive reversal is concentrated on the normal hours period and abnormal returns continue to be positive in the after-hours period that follows the trigger event. This seems to verify that the initial extreme price movement was in fact an overreaction.

As with winners, the magnitude of the reversal for losers after-hours is larger when the losers qualify for the higher trigger level (larger loss). Similar results hold for the twenty-four-hour period in the sequence of the after-hours period when the extreme return was observed.

The reversal tends to be more pronounced in the following period for after-hours winners than after-hours losers. However, in a 24 -hour period the differences in the size of reversal are negligible.

Table 3 depicts the abnormal returns following extreme price variations of ETFs that occurred during normal hours for the full sample of winners and losers and the various subsamples. The contrast with the results obtained previously is stark. Normal hours winners experience not a reversal but a continuation after-hours. This tendency is common to both extreme winners and losers, regardless of the trigger level.

About $50 \%$ of extreme positive price variations (winners) experience negative return on the following after-hours period. It is meaningful that the abnormal returns become negative in the following normal hours period (period 2). This suggests that the continuation which occurred after-hours was wrong and that the investors that operate in this period did not realize that the initial movement corresponded to an overreaction in prices. In spite of the correction observed in period 2 , only between $4.17 \%$ and $7.31 \%$ of the initial extreme movement is offset in the first 24 hours.

The size of the reversal in normal hours and in the first 24 hours after the extreme return is more pronounced for larger triggers.

As with winners, about half of negative extreme price variations (losers) experience positive abnormal returns on the following period. The reversal in the first 24 hours is bigger when a larger trigger level is used. However, the larger the trigger level, the smaller the correction in percentage of the initial extreme return. The size of such reversal in the first 24 hours varies between $6.78 \%$ and $8.44 \%$ of the initial movement. 
Overall, we observe significant differences on responses to extreme price movements between normal hours and after-hours periods. While normal hours extreme price movements do not experience, on average, any reversion on the following period, after-hours extreme abnormal returns show, for the following period, a significant mean reversion of $-1.73 \%$ for winners and $1.41 \%$ for losers, considering a trigger of $5 \%$.

\section{Table 3}

Full sample abnormal returns after normal hours triggers

\begin{tabular}{|c|c|c|c|c|c|c|}
\hline & Normal hours & After-hours & Normal hours & (Period 1-2) & $\begin{array}{l}\text { Continuation (+) or } \\
\text { reversal (-) in the } \\
\text { following period } \\
\text { in proportion } \\
\text { to the initial } \\
\text { extreme return }\end{array}$ & $\begin{array}{l}\text { Continuation (+) } \\
\text { or reversal (-) in } \\
\text { the following } 24 \\
\text { hours in proportion } \\
\text { to the initial } \\
\text { extreme return }\end{array}$ \\
\hline \multicolumn{7}{|c|}{ Panel A. Winners (positive triggers) } \\
\hline \multicolumn{7}{|c|}{ Trigger level } \\
\hline$>=5 \%$ & $7.67 \%$ & $0.28 \%$ & $-0.60 \%$ & $-0.32 \%$ & \multirow{2}{*}{$3.70 \%$} & \multirow{2}{*}{$-4.17 \%$} \\
\hline \multirow[t]{2}{*}{$(\mathrm{N}=10089)$} & $(95.82)^{* * *}$ & $(7.34)^{* * *}$ & $(-3.28)^{* * *}$ & $(-6.36)^{* * *}$ & & \\
\hline & $100 \%: 0 \%$ & $50 \%: 50 \%$ & $47 \%: 53 \%$ & & & \\
\hline$>=6 \%$ & $8.91 \%$ & $0.33 \%$ & $-0.84 \%$ & $-0.51 \%$ & \multirow{2}{*}{$3.72 \%$} & \multirow{2}{*}{$-5.75 \%$} \\
\hline \multirow[t]{2}{*}{$(\mathrm{N}=6212)$} & $(75.94)^{* * *}$ & $(6.47)^{* * *}$ & $(-3.04)^{* * *}$ & $(-18.14)^{* * *}$ & & \\
\hline & $100 \%: 0 \%$ & $50 \%: 50 \%$ & $46 \%: 54 \%$ & & & \\
\hline$>=7 \%$ & $10.10 \%$ & $0.33 \%$ & $-1.07 \%$ & $-0.74 \%$ & \multirow{2}{*}{$3.28 \%$} & \multirow{2}{*}{$-7.31 \%$} \\
\hline \multirow[t]{2}{*}{$(\mathrm{N}=4049)$} & $(61.57)^{* * *}$ & $(5.41)^{* * *}$ & $(-2.66)^{* * *}$ & $(11.52)^{* * *}$ & & \\
\hline & $100 \%: 0 \%$ & $49 \%: 51 \%$ & $44 \%: 56 \%$ & & & \\
\hline \multicolumn{7}{|c|}{ Panel B. Losers (negative triggers) } \\
\hline \multicolumn{7}{|c|}{ Trigger level } \\
\hline$<=-5 \%$ & $-7.47 \%$ & $-0.03 \%$ & $0.66 \%$ & $0.63 \%$ & \multirow{2}{*}{$0.46 \%$} & \multirow{2}{*}{$-8.44 \%$} \\
\hline \multirow[t]{2}{*}{$(\mathrm{N}=12507)$} & $(-95.20)^{* * *}$ & $(3.94)^{* * *}$ & $(13.25)^{* * *}$ & $(8.58)^{* * *}$ & & \\
\hline & $0 \%: 100 \%$ & $52 \%: 48 \%$ & $58 \%: 42 \%$ & & & \\
\hline$<=-6 \%$ & $-8.70 \%$ & $-0.11 \%$ & $0.77 \%$ & $0.65 \%$ & \multirow{2}{*}{$1.29 \%$} & \multirow{2}{*}{$-7.50 \%$} \\
\hline \multirow[t]{2}{*}{$(\mathrm{N}=8057)$} & $(-75.91)^{* * *}$ & $(3.28)^{* * *}$ & $(11.37)^{* * *}$ & $(-2.44)^{* *}$ & & \\
\hline & $0 \%: 100 \%$ & $51 \%: 49 \%$ & $59 \%: 41 \%$ & & & \\
\hline$<=-7 \%$ & $-9.93 \%$ & $-0.19 \%$ & $0.86 \%$ & $0.67 \%$ & \multirow{2}{*}{$1.90 \%$} & \multirow{2}{*}{$-6.78 \%$} \\
\hline \multirow[t]{2}{*}{$(\mathrm{N}=5391)$} & $(-61.82)^{* * *}$ & $(2.78)^{* * *}$ & $(9.76)^{* * *}$ & $(28.25)^{* * *}$ & & \\
\hline & $0 \%: 100 \%$ & $50 \%: 50 \%$ & $59 \%: 41 \%$ & & & \\
\hline
\end{tabular}

Notes: Proportion of positive observations: proportion of negative observations shown in italics.

*,** and ${ }^{* * *}$ represent significance at the $10 \%, 5 \%$ and $1 \%$ levels, respectively, using a 1-tailed test for significance.

Source: Prepared by the authors.

Table 4 compares the size of reversal and continuation between the normal hours and after-hours periods.

\section{Table 4}

Test of difference in mean abnormal returns

\begin{tabular}{ccccc}
\hline Trigger level & AR after normal hours trigger & AR after after-hours trigger & Mean difference & t-stat. \\
\hline $5 \%$ winner & $0.28 \%$ & $-1.73 \%$ & $2.01 \%$ & $(23.42)^{* * *}$ \\
\hline $6 \%$ winner & $0.33 \%$ & $-2.46 \%$ & $2.79 \%$ & $(22.15)^{* * *}$ \\
\hline $7 \%$ winner & $0.33 \%$ & $-3.38 \%$ & $3.71 \%$ & $(20.96)^{* * *}$ \\
\hline $5 \%$ loser & $-0.03 \%$ & $1.41 \%$ & $-1.45 \%$ & $(-10.71)^{* * *}$ \\
\hline $6 \%$ loser & $-0.11 \%$ & $1.94 \%$ & $-2.05 \%$ & $(-10.07)^{* * *}$ \\
\hline $7 \%$ loser & $-0.19 \%$ & $2.67 \%$ & $-2.86 \%$ & $(-10.03)^{* * *}$ \\
\hline
\end{tabular}

*,** and ${ }^{* * *}$ represent significance at the $10 \%, 5 \%$ and $1 \%$ levels, respectively, using a 2 -tailed test for significance.

Source: Prepared by the authors. 
For normal hours winners meeting the $5 \%$ minimum trigger level, the mean continuation after-hours is $0.28 \%$, while for after-hours winners, there is a reversal in the following period of $-1.73 \%$ on average. The mean difference between the two types of reactions is $2.01 \%$, which is statistically different from zero. The results are similar for the $6 \%$ and $7 \%$ trigger levels.

For normal hours losers that qualify for the $5 \%$ trigger, the continuation after-hours is of $-0.03 \%$; for after-hours losers, there is a reversal in the following period of $1.41 \%$ on average. The mean difference between the two types of reactions is $-1.45 \%$, which is again statistically different from zero at conventional levels. The results are similar for the $6 \%$ and $7 \%$ trigger levels.

Thus, the returns observed suggest that there was a significant difference in the reaction in the two different periods. This supports the assertion that normal and afterhours periods may be regarded as two distinct markets.

Since results may differ by ETF type, the analysis is replicated for each type in Table 5 and Table 6 . The 5\% trigger is used again here. Table 5 shows the reaction of ETFs after an initial extreme return occurred during normal hours, while Table 6 shows the results observed after an extreme return that took place after-hours.

Table 5

Abnormal returns after an extreme price movement during normal hours for ETF types

\begin{tabular}{|c|c|c|c|c|c|c|}
\hline & & & Hours & 24 hours & \multirow{2}{*}{$\begin{array}{l}\text { Continuation (+) or } \\
\text { reversal }(-) \text { in the } \\
\text { following period } \\
\text { in proportion } \\
\text { to the initial } \\
\text { extreme return }\end{array}$} & \multirow{2}{*}{$\begin{array}{l}\text { Continuation (+) } \\
\text { or reversal (-) in } \\
\text { the following } 24 \\
\text { hours in proportion } \\
\text { to the initial } \\
\text { extreme return }\end{array}$} \\
\hline & Period 0 & Period 1 & Period 2 & (Period 1-2) & & \\
\hline \multicolumn{7}{|c|}{ Winners (positive triggers) } \\
\hline \multicolumn{7}{|c|}{ ETF type } \\
\hline \multirow{3}{*}{$\begin{array}{l}\text { International ETF } \\
\qquad(\mathrm{N}=1774)\end{array}$} & $7.44 \%$ & $-0.07 \%$ & $-0.59 \%$ & $\begin{array}{c}-0.66 \% \\
(-4.77)^{* * *}\end{array}$ & $-0.98 \%$ & $-8.87 \%$ \\
\hline & $(39.00)^{* * *}$ & $(-0.46)$ & $(-6.21)^{* * *}$ & & & \\
\hline & $100 \%: 0 \%$ & $46 \%: 54 \%$ & $47 \%: 53 \%$ & & & \\
\hline \multirow{3}{*}{$\begin{array}{l}\text { Broad-Based ETF } \\
\quad(\mathrm{N}=3565)\end{array}$} & $7.53 \%$ & $0.41 \%$ & $-0.58 \%$ & $\begin{array}{l}-0.17 \% \\
(-2.42)^{* *}\end{array}$ & $5.47 \%$ & $-2.20 \%$ \\
\hline & $(55.95)^{* * *}$ & $(5.01)^{* * *}$ & $(-8.69)^{* * *}$ & & & \\
\hline & $100 \%: 0 \%$ & $50 \%: 50 \%$ & $49 \%: 51 \%$ & & & \\
\hline \multirow{3}{*}{$\begin{array}{l}\text { Sector ETF } \\
(\mathrm{N}=4750)\end{array}$} & $7.87 \%$ & $0.32 \%$ & $-0.63 \%$ & $\begin{array}{c}-0.31 \% \\
(-4.25)^{* * *}\end{array}$ & $4.07 \%$ & $-3.93 \%$ \\
\hline & $(67.35)^{* * *}$ & $(4.54)^{* * *}$ & $(-10.77)^{* * *}$ & & & \\
\hline & $100 \%: 0 \%$ & $51 \%: 49 \%$ & $46 \%: 54 \%$ & & & \\
\hline \multicolumn{7}{|c|}{ Losers (negative triggers) } \\
\hline \multicolumn{7}{|c|}{ ETF type } \\
\hline \multirow{3}{*}{$\begin{array}{l}\text { International ETF } \\
\qquad(\mathrm{N}=2458)\end{array}$} & $-7.21 \%$ & $0.23 \%$ & $0.54 \%$ & $\begin{array}{c}0.77 \% \\
(4.81)^{* * *}\end{array}$ & $-3.18 \%$ & $-10.65 \%$ \\
\hline & $(-40.67)^{* * *}$ & $(2.39)^{* *}$ & $(4.23)^{* * *}$ & & & \\
\hline & $0 \%: 100 \%$ & $54 \%: 46 \%$ & $59 \%: 41 \%$ & & & \\
\hline \multirow{3}{*}{$\begin{array}{l}\text { Broad-Based ETF } \\
\qquad(\mathrm{N}=4165)\end{array}$} & $-7.51 \%$ & $-0.30 \%$ & $0.68 \%$ & $\begin{array}{c}0.39 \% \\
(2.62)^{* * *}\end{array}$ & $3.96 \%$ & $-5.13 \%$ \\
\hline & $(-55.29)^{* * *}$ & $(-3.55)^{* * *}$ & $(7.43)^{* * *}$ & & & \\
\hline & $0 \%: 100 \%$ & $51 \%: 49 \%$ & $58 \%: 42 \%$ & & & \\
\hline \multirow{3}{*}{$\begin{array}{l}\text { Sector ETF } \\
(\mathrm{N}=5884)\end{array}$} & $-7.55 \%$ & $0.04 \%$ & $0.70 \%$ & $\begin{array}{c}0.75 \% \\
(7.19)^{* * *}\end{array}$ & $-0.56 \%$ & $-9.88 \%$ \\
\hline & $(-66.00)^{* * *}$ & $(0.89)$ & $(9.15)^{* * *}$ & & & \\
\hline & $0 \%: 100 \%$ & $52 \%: 48 \%$ & $57 \%: 43 \%$ & & & \\
\hline
\end{tabular}

Note: Proportion of positive observations: proportion of negative observations shown in italics.

*,** and ${ }^{* * *}$ represent significance at the $10 \%, 5 \%$ and $1 \%$ levels, respectively, using a 1-tailed test for significance.

Source: Prepared by the authors. 
Table 6

Abnormal returns after an extreme price movement during after-hours for ETF types

\begin{tabular}{|c|c|c|c|c|c|c|}
\hline & & & Hours & 24 hours & \multirow{2}{*}{$\begin{array}{l}\text { Continuation (+) or } \\
\text { reversal (-) in the } \\
\text { following period } \\
\text { in proportion } \\
\text { to the initial } \\
\text { extreme return }\end{array}$} & \multirow{2}{*}{$\begin{array}{l}\text { Continuation } \\
(+) \text { or reversal } \\
\text { (-) in the following } \\
24 \text { hours in } \\
\text { proportion } \\
\text { to the initial } \\
\text { extreme return }\end{array}$} \\
\hline & Period 0 & Period 1 & Period 2 & $\begin{array}{l}\text { (Period } \\
1-2)\end{array}$ & & \\
\hline \multicolumn{7}{|c|}{ Winners (positive triggers) } \\
\hline \multicolumn{7}{|c|}{ ETF type } \\
\hline \multirow{3}{*}{$\begin{array}{l}\text { International ETF } \\
\qquad(\mathrm{N}=2308)\end{array}$} & $7.34 \%$ & $-0.91 \%$ & $-0.27 \%$ & \multirow{3}{*}{$\begin{array}{c}-1.18 \% \\
(-9.15)^{* * *}\end{array}$} & \multirow{3}{*}{$-12.41 \%$} & \multirow{3}{*}{$-16.11 \%$} \\
\hline & $(43.92)^{* * *}$ & $(-8.41)^{* * *}$ & $(-3.96)^{* * *}$ & & & \\
\hline & $100 \%: 0 \%$ & $48 \%: 52 \%$ & $45 \%: 55 \%$ & & & \\
\hline \multirow{3}{*}{$\begin{array}{l}\text { Broad-Based ETF } \\
\qquad(\mathrm{N}=1904)\end{array}$} & $7.53 \%$ & $-1.76 \%$ & $-0.07 \%$ & \multirow{3}{*}{$\begin{array}{c}-1.83 \% \\
(-12.50)^{* *}\end{array}$} & \multirow{3}{*}{$-23.35 \%$} & \multirow{3}{*}{$-24.33 \%$} \\
\hline & $(40.91)^{* * *}$ & $(-14.88)^{* * *}$ & $(-1.81)^{*}$ & & & \\
\hline & $100 \%: 0 \%$ & $43 \%: 57 \%$ & $45 \%: 55 \%$ & & & \\
\hline \multirow{3}{*}{$\begin{array}{l}\text { Sector ETF } \\
(\mathrm{N}=2809)\end{array}$} & $7.60 \%$ & $-2.39 \%$ & $0.10 \%$ & \multirow{3}{*}{$\begin{array}{c}-2.29 \% \\
(-18.73)^{* *}\end{array}$} & \multirow{3}{*}{$-31.39 \%$} & \multirow{3}{*}{$-30.08 \%$} \\
\hline & $(50.14)^{* * *}$ & $(-24.59) * * *$ & $(-0.30)$ & & & \\
\hline & $100 \%: 0 \%$ & $39 \%: 61 \%$ & $47 \%: 53 \%$ & & & \\
\hline \multicolumn{7}{|c|}{ Losers (negative triggers) } \\
\hline \multicolumn{7}{|c|}{\begin{tabular}{|l} 
ETF type \\
\end{tabular}} \\
\hline \multirow{3}{*}{$\begin{array}{l}\text { International ETF } \\
\qquad(\mathrm{N}=2259)\end{array}$} & $-7.32 \%$ & $0.76 \%$ & $0.48 \%$ & \multirow{3}{*}{$\begin{array}{l}1.24 \% \\
(7.93)^{* *}\end{array}$} & \multirow{3}{*}{$-10.34 \%$} & \multirow{3}{*}{$-16.96 \%$} \\
\hline & $(-39.61)^{* * *}$ & $(7.20)^{* * *}$ & $(3.52)^{* * *}$ & & & \\
\hline & $0 \%: 100 \%$ & $56 \%: 44 \%$ & $58 \%: 42 \%$ & & & \\
\hline \multirow{3}{*}{$\begin{array}{l}\text { Broad-Based ETF } \\
\qquad(\mathrm{N}=1787)\end{array}$} & $-7.49 \%$ & $1.49 \%$ & $0.41 \%$ & \multirow{3}{*}{$\begin{array}{c}1.90 \% \\
(11.15)^{* *}\end{array}$} & \multirow{3}{*}{$-19.91 \%$} & \multirow{3}{*}{$-25.36 \%$} \\
\hline & $(-36.08)^{* * *}$ & $(12.48)^{* * *}$ & $(2.46)^{* *}$ & & & \\
\hline & $0 \%: 100 \%$ & $60 \%: 40 \%$ & $53 \%: 47 \%$ & & & \\
\hline \multirow{3}{*}{$\begin{array}{l}\text { Sector ETF } \\
(\mathrm{N}=2399)\end{array}$} & $-7.75 \%$ & $1.98 \%$ & $0.42 \%$ & \multirow{3}{*}{$\begin{array}{c}2.40 \% \\
(16.52)^{* *}\end{array}$} & \multirow{3}{*}{$-25.52 \%$} & \multirow{3}{*}{$-30.94 \%$} \\
\hline & $(-43.33)^{* * *}$ & $(19.13)^{* * *}$ & $(2.97)^{* * *}$ & & & \\
\hline & $0 \%: 100 \%$ & $63 \%: 37 \%$ & $53 \%: 47 \%$ & & & \\
\hline
\end{tabular}

Note: Proportion of positive observations: proportion of negative observations shown in italics.

*,** and *** represent significance at the $10 \%, 5 \%$ and $1 \%$ levels, respectively, using a 1-tailed test for significance.

Source: Prepared by the authors.

From Table 5, it is possible to conclude that in most cases the after-hours returns represent a continuation of the extreme returns occurred during normal hours periods. The only statistically significant exception is the reversal of international ETF losers. All types of ETF winners in the normal hours period do not experience a significant reversal after-hours, but they do experience a significant reversal in the subsequent normal hours period. These findings are consistent with those described for the full sample. Regarding the response in the 24-hour period subsequent to the extreme price variation, the reversal of normal hours winners is weaker than the reversal of normal hours losers. In the same 24-hour period, international ETFs present the most pronounced reversal.

Table 5 and Table 6 also highlight the stark contrast between the response to extreme returns observed in normal hours and after-hours. The mean reversal following after-hours winners and losers is statistically significant for all ETF types, although that reversal is stronger for winners than losers. These results are also consistent with those obtained with the full sample. Sector ETFs experience the strongest reversal both in the following period and in the 24-hour period after the extreme return. International ETFs experience the least pronounced reversal in those two periods.

Differences of mean reversals after extreme price movements by types of ETF are summarized on Table 7. We compare the reversals by ETF type within the separate subsamples of day winners, day losers, afterhours winners, and after-hours losers. The 5\% trigger level is used again to identify the ETFs to be considered in each sample. 
Table 7

Comparison of abnormal returns by type of ETF

\begin{tabular}{|c|c|c|c|}
\hline \multicolumn{4}{|c|}{ Panel A. Summary of abnormal returns by type after a $5 \%$ trigger } \\
\hline & International ETF & Sector ETF & Broad-Based ETF \\
\hline Normal hours winners & $-0.07 \%$ & $0.32 \%$ & $0.41 \%$ \\
\hline Normal hours losers & $0.23 \%$ & $0.04 \%$ & $-0.30 \%$ \\
\hline After-hours winners & $-0.91 \%$ & $-2.39 \%$ & $-1.76 \%$ \\
\hline After-hours losers & $0.76 \%$ & $1.98 \%$ & $1.49 \%$ \\
\hline \multicolumn{4}{|c|}{ Panel B. Differences of abnormal return } \\
\hline & AR intl - AR sector & AR intl - AR broad & AR sector - AR broad \\
\hline \multirow{2}{*}{ Normal hours winners } & $-0.55 \%$ & $-0.58 \%$ & $-0.03 \%$ \\
\hline & $(-3.41)^{* * *}$ & $(-4.01)^{* * *}$ & $(-1.04)$ \\
\hline \multirow{2}{*}{ Normal hours losers } & $0.23 \%$ & $0.52 \%$ & $0.28 \%$ \\
\hline & $(1.06)$ & $(3.09)^{* * *}$ & $(1.80)^{*}$ \\
\hline \multirow{2}{*}{ After-hours winners } & $1.71 \%$ & $0.54 \%$ & $-0.89 \%$ \\
\hline & $(10.37)^{* * *}$ & $(3.17)^{* * *}$ & $(-6.18)^{* * *}$ \\
\hline \multirow{2}{*}{ After-hours losers } & $-1.31 \%$ & $-0.45 \%$ & $0.92 \%$ \\
\hline & $(-8.56)^{* * *}$ & $(-3.24)^{* * *}$ & $(5.09)^{* * *}$ \\
\hline
\end{tabular}

*,** and *** represent significance at the 10\%,5\% and 1\% levels, respectively considering a 2-tailed test for significance.

Source: Prepared by the authors.

Panel A of Table 7 summarizes the continuation/ reversals (as measured by abnormal returns), while Panel B shows two-way comparisons. Regarding normal hours periods, international ETFs are the only ones where there is a reversal after-hours. Panel B shows that international and broad-based ETFs experience the greatest difference in their mean reversals. For normal hours losers, there is a significant difference between the response of international ETFs (that exhibit a return reversal) and the response of broad-based ETFs (that exhibit a return continuation).

For after-hours periods, the largest differences are observed between international and sector ETFs, followed by the differences between sector and broad-based ETFs. For after-hours winners and after-hours losers, the reversal of sector and broad-based ETFs is significantly more pronounced than for international ETFs.

Overall, results suggest that, in normal hours periods, international ETFs are the only type that experience an overreaction, leading to a correction after-hours. Sector ETFs exhibit a greater degree of overreaction after-hours, which entails a more pronounced reversal in the following period.

\subsection{Multivariate Analysis of ETF Winners and Losers}

Table 8 and Table 9 show the results of the multivariate analyses of ETF winners and losers. Table 8 shows results for the full sample. All regressions are globally significant with a $1 \%$ significance level. For winner ETFs, the AFTERHOURS binary variable is significantly negative, which indicates that the reversal after an after-hours winner is more pronounced than the reversal following a normal hours winner. This result is consistent with the earlier finding that, on average, reversals among winners occur only following extreme gains observed during after-hours periods. In addition, the trigger variable is significantly negative. The coefficient of -0.377 means that the reversal (loss) is, on average, about $38 \%$ of the previous extreme price variation, after controlling for other variables. The SECTDUM variable is significantly negative at the $10 \%$ level, which indicates that the reversal tends to be stronger for sector ETF winners. This result confirms the previous comparisons of reversals among the three ETF types. The TAXDUM variable is also significantly negative, signaling the existence of relevant tax effects. The year dummies show that there are significant positive unobservable time-specific effects, which suggest that there is a general trend towards less pronounced reversals following positive extreme returns.

An analogous multivariate analysis was employed to examine the full sample of losers. The AFTERHOURS binary variable is significantly positive, indicating that the reversal following an after-hours loser is stronger than the reversal after a normal hours loser. This finding corroborates earlier results. The TRIGGER variable is significantly negative with a coefficient of -0.112 , suggesting that the reversal 
(gain) is $11 \%$ of the previous extreme price variation. The SECTDUM variable is now positive and significant, which suggests that the reversal is more pronounced for sector ETF losers. The TAXDUM binary variable is significantly positive, indicating that the reversal tends to be stronger in the months of December and January. The ABN_VOLUME variable is significantly positive suggesting that the reversals tend to be more pronounced when accompanied by a higher volume of trading. The ABN_VOLATILITY binary variable is significantly negative, meaning that the reversal following extreme losses tends to be stronger when ETF prices are less volatile. The negative coefficients of the year dummies suggest that there is a general trend towards less pronounced reversals following negative extreme returns.

Table 8

Cross-sectional regression of AR after extreme price returns for the whole sample of ETFS

\begin{tabular}{|c|c|c|c|c|}
\hline & Winners & Losers & Normal hours & After-hours \\
\hline \multirow{2}{*}{ Constant } & $0.023^{* * *}$ & -0.002 & $0.004^{* *}$ & 0.007 \\
\hline & $(0.000)$ & $(0.445)$ & $(0.015)$ & $(0.480)$ \\
\hline \multirow{2}{*}{ AFTERHOURS } & $-0.021^{* * *}$ & $0.016^{* * *}$ & & \\
\hline & $(0.000)$ & $(0.000)$ & & \\
\hline \multirow{2}{*}{ LOSDUM } & & & 0.000 & $-0.038^{* * *}$ \\
\hline & & & $(0.940)$ & $(0.009)$ \\
\hline \multirow{2}{*}{ TRIGGER } & $-0.377^{* * *}$ & $-0.112^{* * *}$ & $0.022^{*}$ & $-0.458^{* * *}$ \\
\hline & $(0.000)$ & $(0.001)$ & $(0.064)$ & $(0.000)$ \\
\hline \multirow{2}{*}{ INTLDUM } & 0.002 & 0.000 & 0.001 & 0.001 \\
\hline & $(0.136)$ & $(0.986)$ & $(0.212)$ & $(0.680)$ \\
\hline \multirow{2}{*}{ SECTDUM } & $-0.001 *$ & $0.003^{* * *}$ & $0.001^{* *}$ & -0.001 \\
\hline & $(0.088)$ & $(0.000)$ & $(0.017)$ & $(0.447)$ \\
\hline \multirow{2}{*}{ BULLDUM } & -0.001 & 0.001 & $-0.002 *$ & $0.003^{*}$ \\
\hline & $(0.383)$ & $(0.289)$ & $(0.069)$ & $(0.083)$ \\
\hline \multirow{2}{*}{ TAXDUM } & $-0.009 * * *$ & $0.014^{* * *}$ & $0.001 *$ & $0.003^{*}$ \\
\hline & $(0.000)$ & $(0.000)$ & $(0.063)$ & $(0.097)$ \\
\hline \multirow{2}{*}{ ABN_VOLUME } & -0.000 & $0.000^{* *}$ & 0.000 & 0.000 \\
\hline & $(0.443)$ & $(0.022)$ & $(0.817)$ & $(0.186)$ \\
\hline \multirow{2}{*}{ ABN_VOLATILITY } & 0.002 & $-0.169 * * *$ & 0.021 & -0.005 \\
\hline & $(0.395)$ & $(0.000)$ & $(0.298)$ & $(0.304)$ \\
\hline \multirow{2}{*}{ Year08 } & $0.011 * * *$ & $-0.008 * * *$ & $-0.005^{* * *}$ & $0.011 * *$ \\
\hline & $(0.000)$ & $(0.000)$ & $(0.123)$ & $(0.277)$ \\
\hline \multirow{2}{*}{ Year09 } & $0.006^{* * *}$ & $-0.007 * * *$ & $-0.003 * *$ & 0.008 \\
\hline & $(0.000)$ & $(0.007)$ & $(0.001)$ & $(0.038)$ \\
\hline \multirow{2}{*}{ Year10 } & $0.011^{* * *}$ & $-0.011^{* * *}$ & $-0.003^{* *}$ & $0.011^{* *}$ \\
\hline & $(0.003)$ & $(0.009)$ & $(0.047)$ & $(0.133)$ \\
\hline \multirow{2}{*}{ Year11 } & $0.016^{* * *}$ & $-0.015^{* * *}$ & $-0.004^{* *}$ & $0.009^{*}$ \\
\hline & $(0.000)$ & $(0.000)$ & $(0.038)$ & $(0.049)$ \\
\hline \multirow{2}{*}{ Year12 } & $0.012^{* * *}$ & $-0.013 * * *$ & -0.003 & $0.009^{*}$ \\
\hline & $(0.000)$ & $(0.000)$ & $(0.025)$ & $(0.087)$ \\
\hline \multirow{2}{*}{ Year13 } & $0.008^{* * *}$ & $-0.009 * * *$ & -0.002 & 0.008 \\
\hline & $(0.000)$ & $(0.000)$ & $(0.133)$ & $(0.093)$ \\
\hline \multirow{2}{*}{ Year14 } & $0.014^{* * *}$ & $-0.017^{* * *}$ & -0.003 & 0.006 \\
\hline & $(0.003)$ & $(0.007)$ & $(0.312)$ & $(0.158)$ \\
\hline Observations & 13,909 & 15,704 & 19,389 & 10,224 \\
\hline R-squared & 0.102 & 0.042 & 0.003 & 0.142 \\
\hline $\mathrm{F}$ & 54.35 & 42.57 & 4.666 & 62.33 \\
\hline Prob $>F$ & 0.00 & 0.00 & 0.00 & 0.00 \\
\hline
\end{tabular}

Notes: The dependent variable is the abnormal return $(A R)$ following extreme price returns. AFTERHOURS is a binary variable with a value of 1 if the extreme return occurs after-hours and 0 otherwise. LOSDUM is a binary variable with a value of 1 if the extreme return is negative and 0 otherwise. TRIGGER is the extreme return of the ETF in the initial period. INTLDUM is a binary variable with a value of 1 if the ETF is an international fund and 0 otherwise. SECDTDUM is a binary variable with a value of 1 if the ETF is a sector fund and 0 otherwise. BULLDUM is a binary variable with a value of 1 if the extreme return occurs during a bull market period and 0 otherwise. TAXDUM is a binary variable with a value of 1 if the extreme return occurs during December or January and 0 otherwise. ABN_VOLUME is the abnormal volume traded in the day where the extreme return occurs. ABN_ VOLATILITY is the abnormal standard deviation of returns observed over the past ninety days before the extreme return occurs. YEAR08, YEAR09, YEAR10, YEAR11, YEAR12, YEAR13 and YEAR14 are binary variables with a value of 1 if the extreme return occurs in the year 2008, 2009, 2010, 2011, 2012, 2013 or 2014, respectively, and 0 otherwise. Robust p-value in parentheses. *** $p<0.01$, ** $p<0.05,{ }^{*} p<0.1$.

Source: Prepared by the authors. 
Table 8 also shows the results when the multivariate analysis was conducted considering all the events where the extreme return occurred during normal hours. The TRIGGER variable is positive but only significant at the $10 \%$ level. The coefficient of 0.022 , indicates that, on average, we observe an after-hours continuation of $2.2 \%$ of the initial extreme price movement occurred during the normal hours period. This finding confirms our previous results. The SECTDUM variable is positive and significant at the 5\% level, suggesting that the reversal tends to be more pronounced for sector ETFs. The year dummies show that there are significant negative time-specific effects in the years 2008, 2009, 2010 and 2011.

The same model is estimated for all events where the extreme price variation occurred after-hours. Not surprisingly, the degree of reversal is very strong. The TRIGGER coefficient is now negative (-0.458) and highly significant, indicating a reversal of almost half (46\%) of the initial extreme return. Again, the year dummies capture some positive time-specific effects.

Table 9 displays the results of additional cross-sectional analysis that were conducted for each ETF type. All regressions are globally significant with a $1 \%$ significance level. Results suggest that the determinants of abnormal returns in normal hours and after-hours vary with ETF type. Thus, the reversal of extreme returns observed during normal hours is significantly influenced by the signal of that extreme return in the case of international ETFs (Panel A), by time-specific effects in the case of sector ETFs (Panel B), and by the size of the trigger in the case of broad-based ETFs (Panel C).

Regarding the reaction to extreme returns occurred during after-hours periods, the reversal exists in every ETF type under analysis. In percentage of the initial trigger, the reversal is $57 \%$ in the case of international ETFs, $34 \%$ for sector ETFs and 63\% in the case of broad-based ETFs. The reversal of international ETFs and broad-based ETFs is less pronounced when the initial trigger is negative. In addition, the reversal of extreme returns observed during after-hours is significantly influenced by tax effects in the case of international ETFs (Panel A), by the current stock market trend in the case of sector ETFs (Panel B), and by the volatility in ETF prices in the case of broad-based ETFs (Panel C).

For the sample of international ETF winners (Panel A), the AFTERHOURS binary variable is significantly negative, which means that the reversal (loss) tends to be more pronounced for after-hours winners than normal hours winners. The TRIGGER variable is significantly negative, which implies larger reversals in reaction to larger triggers. The TAXDUM variable is also significantly negative, which means that the reversal tends to be more pronounced in December and January. The ABN VOLATILITY variable is significantly positive, implying that the reversal is larger when the ETF is less volatile.

For the sample of international ETF losers, the AFTERHOURS binary variable is significantly positive, indicating that the reversal (gain) after after-hours losers is more pronounced than for normal hours losers. The TRIGGER variable is significantly negative, which suggests larger reversals in reaction to larger triggers. Tax effects seem to play a role in international ETF losers as the positive and significant value of TAXDUM suggests that reversals are larger during December and January. The ABN_VOLATILITY variable is significantly negative, which indicates again that the reversal is stronger when the ETF volatility is lower. There seem to be some significant negative time-specific effects in the last years of the sample.

For the sector ETF winners (Panel B), the AFTERHOURS, TRIGGER and TAXDUM variables exert an effect that goes in the same direction as the one previously described for the international ETF winners. However, in the case of the sector ETF winners, there are positive time-specific effects in all the years of the sample, except 2013. For sector ETF losers, the AFTERHOURS, TAXDUM and ABN_VOLATILITY variables have a similar effect to the one previously described for the international ETF winners. In addition, there are significant negative time-specific effects in the years 2011 and 2014.

For the broad-based ETF winners (Panel C), the AFTERHOURS, TRIGGER, TAXDUM and ABN VOLATILITY variables exert an effect that goes in the same direction as the one previously described for the international ETF winners. Additionally, the ABN VOLUME variable is significantly negative, which indicates that larger reversals tend to coincide with periods of higher trading volume. Significant time-specific effects continue to be found. For the sample of broad-based ETF losers, AFTERHOURS and TAXDUM are positive and significant, which is consistent with the results obtained for other subsamples of loser ETFs. Moreover, TRIGGER and $\mathrm{ABN}$ _VOLATILITY are significantly negative, which is consistent with the results observed for international loser ETFs. Significant time-specific effects continue to be present.

Although abnormal returns seem to be sensitive to different cross-sectional features in the case of each ETF type, some general conclusions can be provided. First, the reversal tends to be stronger in reaction to the extreme price variations that happen after-hours than those that 
occur during normal hours. Second, the magnitude of the reversal tends to be conditional on the size of the trigger, which entails greater overreaction for specific ETFs with more extreme price variations. Third, the reversal is stronger during the months of December and January, suggesting the presence of relevant tax effects. Fourth, the reversal is usually stronger when the ETF price is less volatile than usual.

Table 9

Cross-sectional regressions of abnormal returns by ETF type after extreme price movements

\begin{tabular}{|c|c|c|c|c|c|c|c|c|c|c|c|c|}
\hline & \multicolumn{4}{|c|}{ Panel A - International ETF } & \multicolumn{4}{|c|}{ Panel B - Sector ETF } & \multicolumn{4}{|c|}{ Panel C - Broad-Based ETF } \\
\hline & $\begin{array}{l}\text { Normal } \\
\text { hours }\end{array}$ & $\begin{array}{l}\text { After- } \\
\text { hours }\end{array}$ & Winners & Losers & $\begin{array}{l}\text { Normal } \\
\text { hours }\end{array}$ & $\begin{array}{l}\text { After- } \\
\text { hours }\end{array}$ & Winners & Losers & $\begin{array}{l}\text { Normal } \\
\text { hours }\end{array}$ & $\begin{array}{l}\text { After- } \\
\text { hours }\end{array}$ & Winners & Losers \\
\hline \multirow{2}{*}{ Constant } & 0.003 & $0.030^{* * *}$ & $0.025^{* * *}$ & -0.003 & $0.011^{* * *}$ & -0.019 & $0.023^{* * *}$ & -0.001 & -0.002 & $0.037^{* * *}$ & $0.023 * * *$ & -0.002 \\
\hline & $(0.372)$ & $(0.002)$ & $(0.002)$ & $(0.662)$ & $(0.000)$ & $(0.183)$ & $(0.000)$ & $(0.820)$ & $(0.458)$ & $(0.000)$ & $(0.000)$ & $(0.658)$ \\
\hline \multirow{2}{*}{ AFTERHOURS } & & & $-0.008^{* * *}$ & $0.006^{* * *}$ & & & $-0.027^{* * *}$ & $0.020^{* * *}$ & & & $-0.022 * * *$ & $0.019^{* * *}$ \\
\hline & & & $(0.000)$ & $(0.000)$ & & & $(0.000)$ & $(0.000)$ & & & $(0.000)$ & $(0.000)$ \\
\hline \multirow{2}{*}{ LOSDUM } & $0.009 * *$ & $-0.067^{* * *}$ & & & -0.003 & -0.008 & & & 0.001 & $-0.063 * * *$ & & \\
\hline & $(0.019)$ & $(0.000)$ & & & $(0.202)$ & $(0.675)$ & & & $(0.750)$ & $(0.000)$ & & \\
\hline \multirow{2}{*}{ TRIGGER } & 0.042 & $-0.567^{* * *}$ & $-0.414^{* * *}$ & $-0.197^{* *}$ & -0.004 & $-0.339 * *$ & $-0.371 * * *$ & -0.072 & $0.053^{* * *}$ & $-0.632^{* * *}$ & $-0.399 * * *$ & $-0.160^{* * *}$ \\
\hline & $(0.122)$ & $(0.000)$ & $(0.000)$ & $(0.023)$ & $(0.843)$ & $(0.012)$ & $(0.000)$ & $(0.106)$ & $(0.004)$ & $(0.000)$ & $(0.000)$ & $(0.000)$ \\
\hline \multirow{2}{*}{ BULLDUM } & -0.003 & 0.002 & -0.004 & $0.005^{*}$ & -0.002 & $0.009 * *$ & 0.000 & 0.002 & -0.001 & 0.001 & -0.002 & 0.000 \\
\hline & $(0.255)$ & $(0.425)$ & $(0.177)$ & $(0.067)$ & $(0.235)$ & $(0.014)$ & $(0.870)$ & $(0.448)$ & $(0.407)$ & $(0.752)$ & (0.305) & $(0.984)$ \\
\hline \multirow{2}{*}{ TAXDUM } & 0.001 & $0.007^{* * *}$ & $-0.012^{* * *}$ & $0.016^{* * *}$ & 0.001 & 0.004 & $-0.008^{* * *}$ & $0.013^{* * *}$ & $0.002^{* *}$ & -0.001 & $-0.013^{* * *}$ & $0.017^{* * *}$ \\
\hline & $(0.519)$ & $(0.001)$ & (0.000) & $(0.000)$ & $(0.522)$ & $(0.165)$ & $(0.000)$ & $(0.000)$ & (0.043) & $(0.865)$ & (0.000) & $(0.000)$ \\
\hline \multirow{2}{*}{$\begin{array}{l}\mathrm{ABN}_{-} \\
\text {VOLUME }\end{array}$} & 0.000 & 0.000 & $0.000^{*}$ & 0.000 & -0.000 & $0.000^{*}$ & 0.000 & 0.000 & -0.000 & -0.000 & $-0.000^{* * *}$ & 0.000 \\
\hline & $(0.335)$ & $(0.210)$ & $(0.071)$ & $(0.151)$ & $(0.805)$ & $(0.068)$ & $(0.106)$ & $(0.703)$ & $(0.544)$ & $(0.197)$ & $(0.004)$ & $(0.186)$ \\
\hline \multirow{2}{*}{$\begin{array}{c}\mathrm{ABN}_{-} \\
\text {VOLATILITY }\end{array}$} & 0.007 & $-0.187^{*}$ & $0.264^{* * *}$ & $-0.287^{* * *}$ & 0.024 & -0.003 & -0.001 & $-0.085^{* *}$ & 0.030 & $-0.468^{* * *}$ & $0.191^{* * *}$ & $-0.270^{* * *}$ \\
\hline & $(0.930)$ & $(0.072)$ & $(0.002)$ & $(0.001)$ & $(0.386)$ & $(0.253)$ & $(0.450)$ & $(0.034)$ & $(0.368)$ & $(0.000)$ & $(0.000)$ & $(0.000)$ \\
\hline \multirow{2}{*}{ Year08 } & $-0.008^{* * *}$ & 0.006 & 0.003 & -0.007 & $-0.009^{* * *}$ & $0.020^{* *}$ & $0.011^{* * *}$ & -0.006 & 0.002 & 0.001 & $0.011^{* * *}$ & $-0.012^{* *}$ \\
\hline & $(0.421)$ & $(0.967)$ & $(0.050)$ & $(0.001)$ & $(0.003)$ & $(0.736)$ & $(0.005)$ & $(0.000)$ & $(0.563)$ & $(0.609)$ & $(0.000)$ & $(0.012)$ \\
\hline \multirow{2}{*}{ Year09 } & $-0.005^{*}$ & -0.003 & -0.006 & -0.007 & $-0.007^{* * *}$ & $0.021^{* * *}$ & $0.008^{* *}$ & -0.004 & 0.003 & -0.007 & $0.008^{* *}$ & $-0.012^{* *}$ \\
\hline & $(0.009)$ & $(0.444)$ & $(0.579)$ & $(0.160)$ & $(0.000)$ & $(0.011)$ & $(0.001)$ & $(0.103)$ & $(0.599)$ & $(0.935)$ & $(0.000)$ & $(0.031)$ \\
\hline \multirow{2}{*}{ Year10 } & $-0.006^{*}$ & 0.001 & $0.011^{*}$ & $-0.017^{* * *}$ & $-0.007^{* * *}$ & $0.024^{* * *}$ & $0.007^{* *}$ & -0.003 & 0.002 & -0.008 & $0.011^{* * *}$ & $-0.015^{* * *}$ \\
\hline & $(0.083)$ & $(0.745)$ & $(0.338)$ & $(0.136)$ & $(0.000)$ & $(0.008)$ & $(0.015)$ & $(0.313)$ & $(0.358)$ & $(0.331)$ & $(0.017)$ & $(0.021)$ \\
\hline \multirow{2}{*}{ Year11 } & -0.005 & 0.003 & $0.012 *$ & $-0.017^{* * *}$ & $-0.009 * * *$ & $0.017^{* *}$ & $0.013^{* * *}$ & $-0.013^{* * *}$ & 0.004 & -0.003 & $0.017^{* * *}$ & $-0.017^{* * *}$ \\
\hline & $(0.071)$ & $(0.874)$ & $(0.070)$ & $(0.001)$ & $(0.001)$ & $(0.003)$ & $(0.028)$ & $(0.400)$ & $(0.535)$ & $(0.279)$ & $(0.001)$ & $(0.009)$ \\
\hline \multirow{2}{*}{ Year12 } & -0.006 & -0.001 & 0.010 & $-0.020^{* * *}$ & $-0.006^{* *}$ & $0.017^{*}$ & $0.008^{* *}$ & -0.005 & 0.002 & -0.007 & $0.019^{* * *}$ & $-0.020 * * *$ \\
\hline & $(0.132)$ & $(0.739)$ & $(0.051)$ & $(0.001)$ & $(0.000)$ & $(0.031)$ & $(0.000)$ & $(0.001)$ & $(0.283)$ & $(0.665)$ & $(0.000)$ & $(0.004)$ \\
\hline \multirow{2}{*}{ Year13 } & -0.003 & 0.002 & 0.010 & $-0.016^{* * *}$ & $-0.006^{* * *}$ & 0.007 & 0.003 & -0.005 & 0.003 & 0.005 & 0.004 & -0.002 \\
\hline & $(0.211)$ & $(0.921)$ & $(0.121)$ & $(0.000)$ & $(0.011)$ & $(0.056)$ & $(0.030)$ & $(0.342)$ & $(0.585)$ & $(0.322)$ & $(0.000)$ & (0.006) \\
\hline \multirow{2}{*}{ Year14 } & -0.005 & -0.000 & $0.013^{* *}$ & $-0.020 * * *$ & $-0.007 * * *$ & 0.003 & $0.011^{* * *}$ & $-0.016^{* * *}$ & 0.002 & -0.004 & $0.015^{* * *}$ & $-0.017^{* *}$ \\
\hline & $(0.453)$ & $(0.820)$ & $(0.106)$ & $(0.004)$ & $(0.009)$ & $(0.440)$ & $(0.460)$ & $(0.219)$ & $(0.432)$ & $(0.607)$ & $(0.328)$ & $(0.787)$ \\
\hline Observations & 3,410 & 3,712 & 3,263 & 3,859 & 9,198 & 3,771 & 6,097 & 6,872 & 6,781 & 2,741 & 4,549 & 4,973 \\
\hline R-squared & 0.003 & 0.132 & 0.077 & 0.037 & 0.003 & 0.141 & 0.114 & 0.046 & 0.013 & 0.209 & 0.128 & 0.060 \\
\hline $\mathrm{F}$ & 1.596 & 14.47 & 10.18 & 11.29 & 3.571 & 42.97 & 35.74 & 22.18 & 6.753 & 30.01 & 26.31 & 20.64 \\
\hline Prob $>F$ & 0.08 & 0.00 & 0.00 & 0.00 & 0.00 & 0.00 & 0.00 & 0.00 & 0.00 & 0.00 & 0.00 & 0.00 \\
\hline
\end{tabular}

Note: The dependent variable is the abnormal return $(A R)$ following extreme price returns. AFTERHOURS is a binary variable with a value of 1 if the extreme return occurs after-hours and 0 otherwise. LOSDUM is a binary variable with a value of 1 if the extreme return is negative and 0 otherwise. TRIGGER is the extreme return of the ETF in the initial period. BULLDUM is a binary variable with a value of 1 if the extreme return occurs during a bull market period and 0 otherwise. TAXDUM is a binary variable with a value of 1 if the extreme return occurs during December or January and 0 otherwise. ABN_VOLUME is the abnormal volume traded in the day where the extreme return occurs. ABN_VOLATILITY is the abnormal standard deviation of returns observed over the past ninety days before the extreme return ocCUrS. YEAR08, YEAR09, YEAR10, YEAR11, YEAR12, YEAR13 and YEAR14 are binary variables with a value of 1 if the extreme return occurs in the year 2008, 2009, 2010, 2011, 2012, 2013 or 2014 , respectively, and 0 otherwise. Robust $p$-value in parentheses. ${ }^{* * *} p<0.01,{ }^{* *} p<0.05,{ }^{*} p<0.1$.

Source: Prepared by the authors. 


\section{CONCLUSION}

ETFs hold a fixed basket of stocks, similar to a mutual fund, but they may be traded throughout the day at prices determined by the market on a stock exchange. ETFs provide an easy way for less informed investors to assume positions in stock composites, which could imply the formation of more volatile prices in the market.

Our paper examines the response to the variations in the share price of ETFs that happen within either normal trading hours and after-hours (at least 5\% in either direction). Based on an analysis of 36,962 extreme price variations of US ETFs in the 2007-2014 period, we documented a stark contrast between what occurs in normal hours and after-hours. We show that there is a much stronger reversal of extreme price variations that occur after-hours. In fact, on average only extreme returns that happen after-hours tend to be reversed in the following period. This result lends credit to the notion that normal and after-hours periods may be regarded as two separate markets and corroborates the literature suggesting that markets during after-hours tend to be more inefficient (e.g., Barclay \& Hendershot 2003; Berkman et al. 2012).

The existence of a significant overreaction in ETF prices is somewhat surprising, given that these instruments offer most advantages of a future contract such as liquidity and competitive pricing. They can be purchased on margin and sold short. Moreover, unlike most mutual funds, each ETF has a very specific investment objective, such as replicating a country's stock index or an industry sector. Because ETFs have clearly defined objectives and are easy to trade, their prices should, in theory, closely follow fundamentals. Our results suggest that, in spite of these favorable characteristics, noise traders can significantly influence the short-term evolution of ETF prices. Other reasons such as changing risk premia or microstructure influences seem unlikely candidates to explain the reported patterns of short-term overreaction and reversal.

On the basis of multivariate analyses, we conclude that reversals are consistently stronger for ETFs that experienced more extreme price movements. Moreover, the reversal tends to be stronger during the months of
December and January. This finding suggests that taxmotivated trading is important to understand short-term price overreaction. So, one should take into account these effects in future research.

The reversal is found to be usually more pronounced when the ETF price is less volatile. This finding lends supports to the proposition that uninformed investors that are at the origin of the overreaction movement can also create abnormal volatility and noise trader risk that reduces arbitrage effectiveness in the short-term.

Our results have important implications for both regulator and market practitioners' purposes. First, as regards regulation, our findings advise market regulators to concentrate their resources on the oversight of the ETF pricing that occurs after-hours. The existence of overreaction in prices imply that some investors trade too much; and consequently they bear unnecessary trading costs. These excessive trading costs are found to be very significant economically: according to some estimates stock market investors incur in losses that can reach between $0.7 \%$ and $2.2 \%$ of their respective national GDP, every year (French 2008; Barber et al., 2008). Regulators should be concerned with this loss of wealth also in the case of ETF markets. Second, for market practitioners, our findings suggest the existence of profitable market opportunities. During the sample period, for after-hours winners qualifying for the $5 \%$ minimum trigger, the mean reversal in the following period is $-1.73 \%$, while for afterhours losers, there is a reversal of $1.41 \%$ on average (see table 2). Bid-ask spreads can be significant for ETFs that have low liquidity. However, it should be noted that in order to take advantage of the overreaction patterns detected in our paper, the investor would have to trade during normal hours, precisely the period in which the concern with the lack of liquidity is least justified. In fact, considering the relatively low costs of investing in liquid ETFs during normal hours and that the bid-ask spread on large capitalization US ETF lies typically between $0.1 \%$ and $0.2 \%$ of share price (Golub et al., 2013), our results suggest that there is room to profit from the above mentioned pattern of overreaction and reversal at least in highly liquid ETFs. 


\section{REFERENCES}

Atkins, A., Dyl, E. 1990. Price Reversals, Bid-Ask Spreads, and Market Efficiency. Journal of Financial and Quantitative Analysis, 25, 535-547.

Barber, B. M., Lee, Y., Liu, Y., Odean T. 2008. Just How Much Do Individual Investors Lose by Trading? Review of Financial Studies, 22, 609-632.

Barclay, M.J., Hendershott, T. 2003. Price Discovery and Trading After Hours. Review of Financial Studies, 16, 1041-1073.

Berkman, H., Koch, P., Tuttle, L., Zhang, Y. 2012. Paying Attention: Overnight Retums and the Hidden Cost of Buying at the Open. Journal of Financial and Quantitative Analysis, 47, 715-741.

Bowman, R.G., Iverson, D. 1998. Short-run overreaction in the New Zealand stock market. Pacific-Basin Finance Journal, 6, 475-491.

Bremer, M., Sweeney, R.J. 1991. The reversal of large stock-price decreases. Journal of Finance, 46, 747-754.

Bremer, M., Hiraki, T., Sweeney, R.J. 1997. Predictable patterns after large stock price changes on the Tokyo Stock Exchange. Journal of Financial and Quantitative Analysis, 32, 345-365.

Brown, S.J., Warner, J.B. 1980. Measuring Security Price Performance. Journal of Financial Economics, 8, 205-258.

Brown, K.C., Harlow, W.V., Tinic, S.M. 1993. The risk and required return of common stock following major price innovations. Journal of Financial and Quantitative Analysis, $28,101-116$.

Caporale, G.M., Gil-Alana, L., Plastun, A. 2017. Short-Term Price Overreactions: Identification, Testing, Exploitation. Computational Economics, forthcoming, DOI: 10.1007/ s10614-017-9651-2.

Choi, H.S., Jayaraman, N. 2009. Is reversal of large stock-price declines caused by overreaction or information asymmetry: Evidence from stock and option markets. Journal of Futures Markets, 29, 348-376.

Cox, D.R., Peterson, D.R. 1994. Stock returns following large oneday declines: Evidence on short-term reversals and longerterm performance. Journal of Finance, 49, 255-267.

Davis, S., Madura, J., Marciniak, M. 2009. Performance and Risk among Types of Exchange-Traded Funds during the Financial Crisis. Journal of Derivatives, 1, 182-188.

De Bondt, W.F.M., Thaler, R.H. 1985. Does the Stock Market Overreact? Journal of Finance, 40, 793-805.
De Bondt, W.F.M., Thaler, R.H. 1987. Further Evidence on Investor Overreaction and Stock Market Seasonality. Journal of Finance, 42, 557-581.

French, K. 2008. Presidential Address: The Cost of Active Investing. Journal of Finance, 63, 1537-1573.

Golub, B., Novick, B., Madhavan, A., Shapiro, I., Walters, K., Ferconi, M. 2013. Viewpoint: Exchange Traded Products: Overview, Benefits and Myths. BlackRock Investment Institute.

Levy, A., Lieberman, O. 2013. Overreaction of Country ETFs to US Market Returns: Intraday vs. Daily Horizons and the Role of Synchronized Trading. Journal of Banking and Finance, 37, 1412-1421.

Lobe, S., Rieks, J. 2011. Short-term market overreaction on the Frankfurt stock exchange. Quarterly Review of Economics and Finance, 51, 113-123.

Madura, J., Richie, N. 2004. Overreaction of Exchange-Traded Funds during the Bubble of 1998-2002. Journal of Behavioral Finance, 5, 91-104.

Mazouz, K., Joseph, N.L., Joulmer, J. 2009. Stock price reaction following large one-day price changes: UK evidence. Journal of Banking \& Finance, 33, 1481-1493.

Otchere, I., Chan, J. 2003. Short-term overreaction in the Hong Kong stock market: Can a contrarian trading strategy beat the market? Journal of Behavioral Finance, 4, 157-171.

Pagan, A.R., Sossounov, K.A. 2003. A Simple Framework for Analysing Bull and Bear Markets. Journal of Applied Econometrics, 13, 23-46.

Simon, D.P., Sternberg, J.S. 2005. Overreaction and Trading Strategies in European iShares. Journal of Alternative Investments (Summer), 29-41.

Spyrou, S., Kassimatis, K., Galariotis, E. 2007. Short-term overreaction, underreaction and efficient reaction: Evidence from the London Stock Exchange. Applied Financial Economics, 17, 221-235.

Stambaugh, R.F., Jianfeng, Y., Yuan, Y. 2012. The Short of It: Investor Sentiment and Anomalies. Journal of Financial Economics, 104, 288-302.

Tse, Y., Martinez, V. 2007. Price discovery and informational efficiency of international iShares funds. Global Finance Journal, 18, 1-15. 